\title{
Laboratory Information Management System Design for Food Practice Course Education
}

\author{
Wu Dan*, Cheng Huan, Li Yang, Wu xiaoqin, Chen Shiguo, Chen Qihe, Liu \\ Donghong \\ College of Biosystems Engineering and Food Science, Zhejiang University, Hangzhou, 310058, China \\ *Corresponding author. E-mail: wudan2008@zju.edu.cn
}

\begin{abstract}
Laboratory is the most important components in university. Its modernization and informatization are the important construction contents for standardization. With the acceleration of teaching reform in universities, a consensus has been reached on laboratory opening and resource sharing. Therefore, an information-based process management tool suitable for both undergraduate experiment teaching and graduate research experiment is urgently needed. A laboratory information management system (LIMS) is proposed base on advanced information technology for food practice course education, which include laboratory safety management, laboratory resources management and experimental execution management. Laboratory safety management includes laboratory safety learning and safety knowledge Test module; laboratory resources management includes instrument management, chemical reagents management and material management module, it has good storage address function; experimental execution management includes laboratory use sign-in sign-out, chemical reagents use sign-in sign-out and instrument use signin sign-out based on two-dimensional code(TDC) technology. This system can provide better services for teaching and scientific research, effectively improve the experimental safe and experiment efficiency, regulate the use of instruments and reagents, and further standardize the management of the laboratory. The system can be extended to the related chemical practice course education.
\end{abstract}

Keywords: Laboratory, Information, Food practice, Management system, chemical practice.

\section{INTRODUCTION}

Laboratory is an important place for college students to conduct practical learning, It is also the main place for scientific research and innovation experiments [1]. With computer technology' development, It has been widely applied in university laboratories management. The construction of laboratory information has been an integral part of the construction of colleges and universities [2-5].

The food industry is a traditional industry, and the talents demand for food technology is constantly increasing. According to the statistics, the food market revenue would increase at a rate of $4.8 \%$ a year in Asia a [6] The annual demand for food industry employees is increasing, the food industry will need about 140,000 employees until 2024 supposed by the Food and Drink Federation of U.K [7]. According to the prediction of the food industry association in China, the annual increase of labor force in Shanghai food enterprises is about 6,500 people, and the demand for food professionals will be further increased by $5 \%$ per year, and at the same time, all enterprises pay more attention to employees' practical operation and innovation ability [8]. There have been more than 100 colleges and universities offering food majors in China. Some practice teaching courses, include food analysis experiment, food chemical experiment and food processing experiment and so on, are the compulsory courses. The innovative experiment of food science major is an important goal of the current development and construction of discipline and university, include its informational construction $[9,10]$. Laboratory information management systems is carried out to achieve high efficiency with work or teaching in company or university [11], and at the same time, by expanding the framework of the systems, it would have the function to improve laboratory safety [12]. In the experimental teaching reform of food specialty, the exploratory experiment has been added. That encourages students to design experimental schemes by themselves, prepare experimental materials, carry out 
experiment, analyze experimental data and then extrapolate to the conclusion independently. In the whole process of the experiment, the teacher mainly plays a guiding role, and the students conduct independent research on different experimental subjects by themselves. Compared with traditional experimental teaching methods, "exploratory experiment" has complex and changeable. The original laboratory management system can not fully meet the teaching reform, new information-based laboratory management tools are urgently needed, which requires open laboratories and resource sharing, especially for chemical reagents usage, instruments usage and experimental safety.

When using the search term "laboratory management system" in title, abstract or author-specified keywords of articles in web of "www.sciencedirect.com", 3618 articles were obtained; using the search term "laboratory information management system", 909 articles were obtained; using the search term "laboratory information management system and food ", 31 articles were obtained; using the search term "laboratory information management system and food education"or "laboratory information management system and food teach", only 4 articles were obtained. There is only one report that described the importance of LIMS for food processing factories [13], but few report about information reform of food specialized laboratory in university.

In order to adapt to the experimental teaching mode in the new situation, it is necessary to accelerate the information management mode of laboratories. A laboratory information management system is proposed base on advanced information technology, which include laboratory safety management, laboratory resources management and experimental execution management. The system has standardized the behavior of the laboratory administrator and the user. It requires the students to learn the experimental safety knowledge and pass its safety test before he or she enter lab. The Eclipse framework is used for standardized laboratory management of chemical reagents and consumables, which makes it easy for students and teachers to find the goods, use it and return it to their positions. The instruments must start by scanning the TDC code, the administrators can easily keep knowledge of the use information of the instrument with TDC code and a use record software, whether the instrument is high value or low value.

\section{LABORATORY INFORMATION MANAGEMENT SYSTEM(LIMS)}

\subsection{Technical background}

The innovation and reform of higher education cannot be separated from the reform of educational information, and the laboratory, as an important practice place of higher education, must follow the pace of educational reform and walk in the forefront of the construction of information. As one of the best universities in China, Zhejiang University has been in the forefront of educational reform. It has own unique experience in the laboratory management, in order to strengthen laboratory safety, and improve instruments use efficiency, there are more than 5 information management systems developed, including laboratory safety examination system, laboratory safety information system, equipment management system, large instrument reservation system, materials and chemicals procurement system, etc. These systems standardize the students' experiment safety behavior on a macro level and promote the standard use of laboratories and instruments. But these systems only provide solutions to common technical problems, they can't meet the specialized needs that arise in different professional courses. In the food practice course, the current exploratory experimental practice course emphasizes the initiative of students, requires students to design their own experimental scheme, prepare their own experimental materials, and complete the whole experimental work. This requires students to be familiar with the reagents, consumables and instruments in the laboratory, and know exactly the address of the needed reagents and instruments in time and carry out the experiment. In ordinary routine food chemical experiments, the reagents, consumables and small instruments are not fixed in the lab. Students can change their positions according to their experiment needs. The chemical reagents will be taken out of the medicine cabinet when needed, but it will be forgot the original storage position in the cabinet after used, such as which rows and floors in cabinet. While the reagents cabinet may store hundreds of chemical reagents, if the chemical reagent cannot be put back in the same place before, the next student needs to spend lot of time searching. It will waste a lot of preparation time for experiments. At the same time, the reagent will be purchased repeatedly if not found. If there is an information system to manage the specific address of reagents, students can query the address of the reagent and put it back to the original position after using the drug, then the search and preparation of experimental drugs can save a lot of time. The system will improve the efficiency of the experiment and reduce the waste of drugs, it is also have the same effect on the consumables and small instruments in the lab. The information system with the specific address function of chemical reagents, consumables and small instruments can further standardize the specific operation of students in the specific experiment process, promote the development of independent explore experiment, and improve the level of laboratory safety management.

On the other hand, the school's instrument management platform only supply the use of the 
instrument appointment, and cannot fully understand the actual operation of the instrument. Therefore, it is necessary to develop a use record software that matches the actual operation of the instrument, and strengthen the management of the instrument.

This project puts forward a new idea of laboratory information management system under the above background and the previous experience [14].

\subsection{Basic Frame Design}

The laboratory information management system frame is designed in figure1. Its development and runtime environments are as follows:

(1) Hardware environment: ordinary PC server.

(2) Operating system: based on the operating system after Linux Kernerl 2.6.x. Install the system plug-in first: Microsoft.net. Framework3.5.
(3) Running environment: Apache is used as the HTTP server.

(4) Database server: MySQL 5.0.

(5) Development language: PHP.

(6) Development tool: Eclipse.

(7) Client requirements: the client has IE6. 0 or above browsers. If you don't have Internet Explorer, you can also use Chrome, Firefox, Safari and other browsers.

The system supports teachers and students to log in the system with different identities, guide them to learn safe knowledge, inquiry instrument-reagent information, appoint instrument, use instrument and operate confirmation on site. Users are experimental teachers, laboratory administrators, experimental students, scientific research teachers and so on. The system displays the different function modules corresponding to users' different identities when logging in.

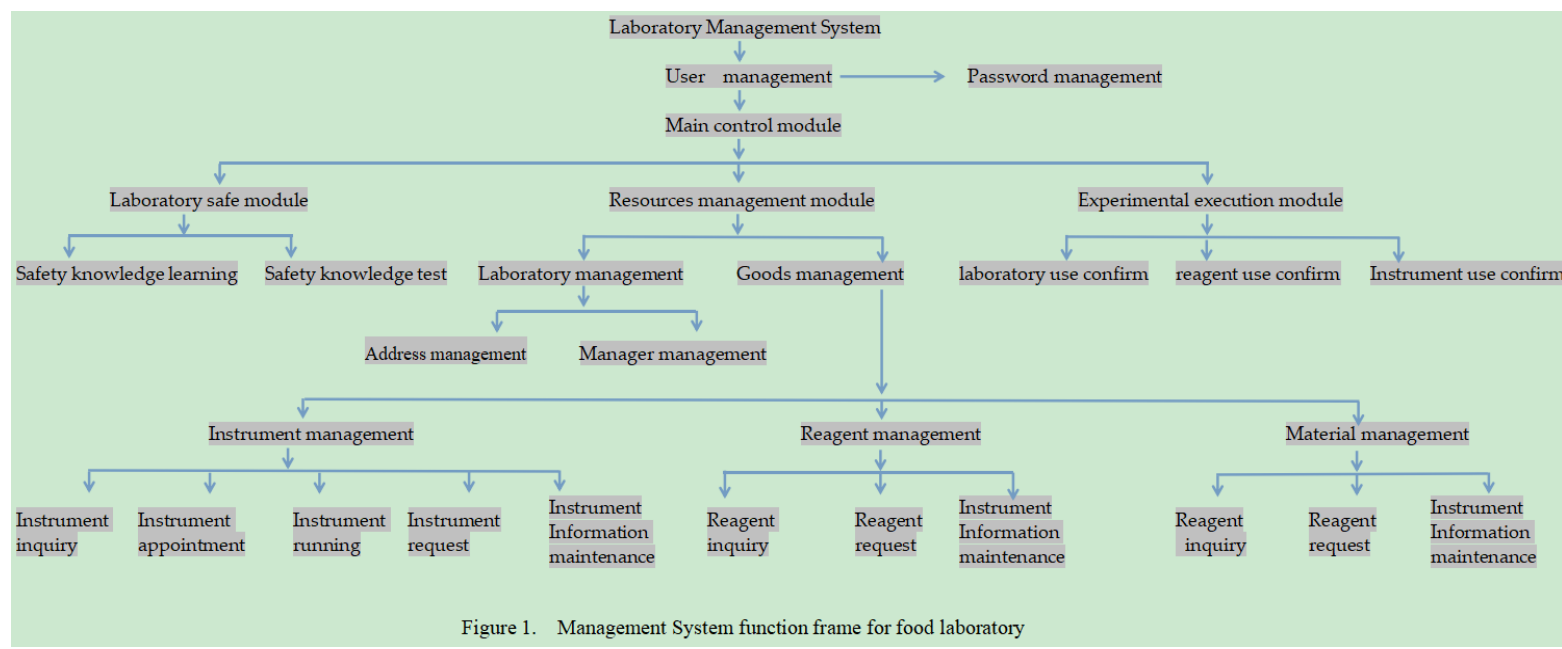

\subsection{Basic Frame Design}

The system includes 3 main function modules, they are laboratory safe management, laboratory reagentinstrument management and experimental execution management.

\subsubsection{Laboratory safe module}

This module includes safety knowledge learning and safety knowledge test. The safety knowledge includes the rules and regulations of the laboratory, the rules and regulations of the instruments use, and the rules and regulations of chemical reagents use. Laboratory is a key unit of fire and is easy to have safe accidents. experimental safety should be placed in the first place. Three precautions should be bringing to the attention when students and teachers is conducting the experiment in food science lab:

(1) To prevent corrosion, chemical burns, scalds and
(2) To prevent explosion and combustion.

(3) To prevent poisoning.

The teacher and student are required to correctly identify and analyze the sources of risk in the laboratory. Avoid safety accidents caused by weak awareness of laboratory safety and lack of understanding of laboratory conditions.

\subsubsection{Resources management}

The laboratory management module can add 3 levels of laboratories, including university level laboratory center, college level laboratory center and specific laboratory. The administrator can add, modify and delete the name of the experimental center in the parent directory, and can also add, delete and modify the address and name of the specific laboratory in the parent directory and child directory, and complete the member setting of different laboratories. Labs at the same level can be sorted differently as needed. Adjustments can be cuts. 
made when a specific laboratory in the lab center is assigned to another lab center.

The good management module has good storage address function, it was divided into three parts: instrument management, reagent management and material management. The query function of three parts is set up as follows: query and summary by product name, query and summary by laboratory address, query and summary by experiment subject name, and query and summary by the category. The information maintenance function of three parts mainly supplies information such as storage location, category, specification, quantity, price, manufacturer. In the case of reagent chemicals, the hazard level, CAS number, precautions and other information should also be displayed. It has the function of batch editing, modifying and emptying the reagents and instruments. Chemicals of different danger grades are required to be classified and placed in different chemical cabinets. The request function of three parts allows teachers or students to apply for the purchase of new instruments, reagents and normal materials according to the experiment projects. It is helpful for the experimental teaching center to do well in the budget of the experimental material in advance.

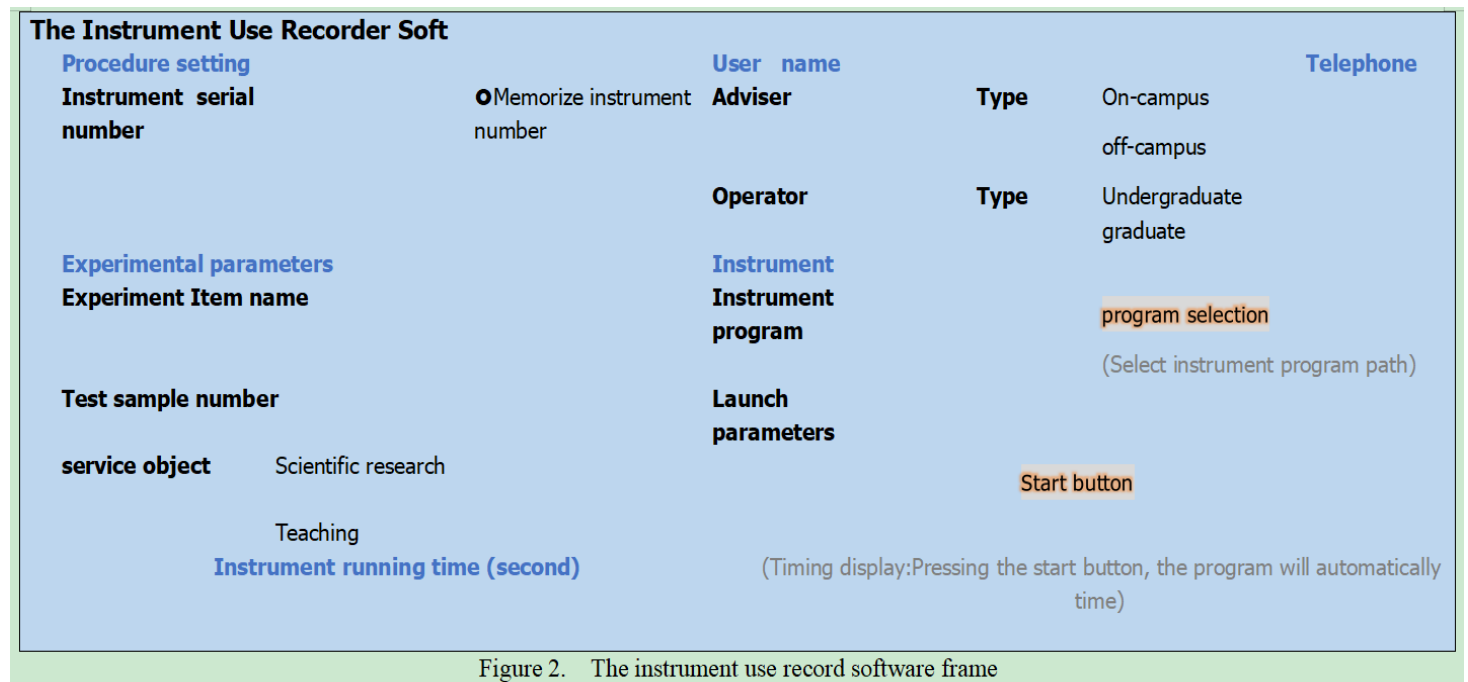

In addition, the instrument management has appointment management and running management function. The running management function is mainly for the management of large and expensive instruments, which usually is operated by instrument software in a computer. It depends on an instrument use record software, which is showed in figure 2 . When students use lab equipment with computers, the software starts with the computer and asks students to fill in lab information. Once the information is completed, the software will assist in starting the instrument software. After the completion of the experiment, a record of the use of the instrument will be generated automatically, including the user name, the experiment item, sample number, service object (teaching or research), personnel category (postgraduate or undergraduate), contact phone number, and the operation time of the instrument. The instrument appointment function not only supplies appointment function, but also supplies instructions, procedures and guidance video for the use of instruments.

\subsubsection{Experimental execution management}

The implementation of this module requires the support of two-dimensional code technology. Experimental execution management requires each specific laboratory to have a TDC code address, which is associated with the laboratory management module in "resources management" section. Paste the TDC code label on the door of the corresponding lab, when students and teachers want use the lab, they scan the TDC code to confirm the use, the lab door can be automatically opened. After finished the experiment, the lab door will be automatically closed by scanning the code again. By the same way, TDC code can be used to monitor each experimental equipment usage by controlling power switch, students and teachers scan equipment power switch TDC code to use the instrument, and confirm finishing by scan again; TDC code can also be used to monitor different danger grade chemical-reagent use by controlling chemicals cabinet lock, students and teachers scan TDC on chemicals cabinet to confirm using and returning chemicals. When scanning the TDC code, it is required to fill in the use of student and teacher name, number, institute and contact information, the use record is automatically formed and transmitted to the server terminal at the end. In the management of experimental equipment, the combination of TDC code technology and instrument use record software in section "resources management" can manage the use information of all kinds of instruments from high value to low value, from complex to simple. The TDC code technology of chemical cabinet provides technical support for the safe use of chemicals. The TDC code technology combination use of laboratory, experimental instrument and experimental chemical cabinet will greatly improve the 
efficiency of laboratory management. The laboratory manager can timely understand the real-time use status of different laboratories, different instruments and different chemical cabinets through the two-dimensional code server information terminal.

\section{PREDICTION EFFECT OF LIMS}

The LIMS is designed for college students to conduct practical learning, especially for scientific research and innovation experiments by themselves. It includes laboratory safety management, laboratory management, reagent-instrument management and experimental execution management. The system has standardized the behavior of the laboratory administrator and the user. It supports lab opening and resource sharing, especially for chemical reagents usage, instruments usage and experimental safety.

The system will show the following advantages:

(1) The laboratory safe module standardizes the study of experimental safety knowledge. The operator who has passed the experimental safety knowledge test can enter the laboratory for experiments. The user's awareness of experimental safety is strengthen by this way, and the level of experimental safety management effectively improved.

(2) In the process of experiment design and reagent preparation, students and teachers can login the laboratory system through the web services, query the instrument and chemical reagent information at any time and place. It promotes resource sharing and opening of lab. If there is a lack of instruments, reagents or consumables, the laboratory administrator can get information in time. The system improve the efficiency of experimental teaching in lab management.

(3) The system has the function of instrument and reagent storage address management. The teacher and student can quickly find the instrument or reagent through the system whether he or she is familiar with the laboratory or not, and they can return the goods after finishing experiment according to the system suggested. The system effectively strengthens the experimental process management, promotes the standard use of instruments and reagents, reduces the waste of chemical reagents effectively and improves the experimental efficiency.

(4) In the management of experimental equipment, combination of the TDC code technology and the instrument use record software can improve the work efficiency of laboratory administrator. By exporting the automatically generated usage record data, the administrator can count the total hours that the instrument serves for a certain user in different periods of time. In additionally, the use time for the instrument for a certain scientific research projects can be counted by the instrument use record software.

(5) Experimental execution management can improve laboratory administrators knowing the real-time use status of different laboratories, different instruments and different chemical cabinets.

All in all, the implementation of the system promotes the opening and sharing of experimental teaching platform, accelerates the construction of experimental teaching informatization, strengthens the management of experimental teaching process, and promotes the effective and standardized experimental teaching and scientific research.

\section{CONCLUSION}

With the development of informatization in modern society, higher education has gradually entered the age of online, big data and intelligence, especially in epidemic situation of COVID-19 [15-18], including the informatization of talent training, experimental teaching and laboratory management [19-21]. The informatization of laboratory management also contributes to promote laboratory safety, promote the modernization of experimental teaching and promote the education system reform of talent cultivation. This laboratory information management system proposed can integrate the lab resources of the whole school, provide comprehensive laboratory information openly for undergraduate and graduate students' scientific practice activities. The system promotes lab information sharing and exchange, and improves students' practical efficiency. It can provide information data to administrator for scientific decision; promote the development of experimental technology and scientific research level.

\section{AUTHORS' CONTRIBUTIONS}

Design the project and writing the manuscript, D.W.; System management and maintenance, C.H. , L.Y, W.X., C.S., C.Q. and L.D. All authors have read and agreed to the published version of the manuscript.

\section{ACKNOWLEDGMENTS}

This research was supported by The Teaching Reform Project of Food Science Based on The New International Certification System of the Institute of Food Technologists(IFT) (Grant Number: zdjg21015). The authors thank engineer Chen Lin-bo and Hangzhou Lohand Biological Technology CO., Ltd for technology support.

\section{REFERENCES}

[1] Huang, T. Research on information class laboratory management based on cloud platform. In 2018 15th 
International Symposium on Pervasive Systems, Algorithms and Networks (I-SPAN), IEEE,2018, pp. 127-132.

[2] Prado, G. A new food engineering elective course for chemical engineering students. Education for Chemical Engineers,2021,35, 105-115.

[3] Santelices, J. V.; Comendador, B. E. V. RFID Integrated Computer-Aided Laboratory Support Services (RFID ICLASS). International Journal of Future Computer and Communication, 2016, 5(2), 130.

[4] Ugwuanyi, C. S.; Okeke, C. I.. Enhancing university students' achievement in Physics using computer-assisted instruction. International Journal of Higher Education,2020, 9(5), 115-124.

[5] Wei, C. Research on university laboratory management and maintenance framework based on computer aided technology. Microprocessors and Microsystems,2020,103617. https://doi.org/10.1016/j.micpro.2020.103617.

[6] Food Market, 2020. Statista, Available: https://www.statista.com/outlook/40000000/101/fo od/asia\#: :text=Revenue $\% 20$ in $\% 20$ the $\% 20$ Food $\%$ 20market, US\%24582\%2C527m\%20in\%202020. Accessed December 9, 2020.

[7] Food and Drink Federation, 2020. Economic Contribution and Growth Opportunity. Food and Drink Federation, Available: http://www.fdf.org.uk/economic-contribution.aspx. Accessed December 9, 2020.

[8] Zhao, Y.; li, N.; Zhao, L.; Zhao, S.; Tang Y. The Development of Bakery Food Industry in Shanghai. Food Industry(china), 2020, 41(04):239-243.

[9] Chen, Y.; Jiang D.; Chong Y.; Chen J.; Zhou Y.; Fang, S. Exploration of Informationization Management Model on Food Engineering Experiment Teaching. Research and Exploration in Laboratory(China). 2020, 39(9):255-258.

[10] Tao, J.; Zhan, G.; Cao, X. Construction and research of laboratory information system based on $\mathrm{PaaS}$ in colleges and universities, Experimental Technology and Management(china), 2020,37(12):277-280.

[11] Poonam, J.P.; Bodhe, G.L. Trends in laboratory information management system. Chemometrics and Intelligent Laboratory Systems, 2012, 118, 187-192.

[12] Sun, D.; Wu, L.; Fan, G. Laboratory information management system for biosafety laboratory: Safety and efficiency. Journal of Biosafety and
Biosecurity, 2021,3(1): 28-34, https://doi.org/10.1016/j.jobb.2021.03.001.

[13] Çă̆ındı, Ö.; Ötleş, S. Importance of laboratory information management systems (LIMS) software for food processing factories. Journal of Food Engineering, 2004,65(4): 565-568.

[14] Wu, D.; Chen, L. Design and Development of Laboratory Management System of Instruments and Chemical Reagents for Innovative Experimental Teaching. Research and Exploration in Laboratory(China), 2016,35(10):296-298,303.

[15] Eun, P.Y. A data-driven approach for discovery of the latest research trends in higher education for business by leveraging advanced technology and big data. Journal of Education for Business, 2021, 96(5) : 291-298.

[16] Fan, W. Development path of basic education based on 5G technology and multimedia embedded system.Microprocessors and Microsystems,2021,82, 103850. https://doi.org/10.1016/j.micpro.2021.103850.

[17] Renz, A.; Hilbig, R. Prerequisites for artificial intelligence in further education: identification of drivers, barriers, and business models of educational technology companies. International Journal of Educational Technology in Higher Education, 2020, 17(4) : 86-108.

[18] Yao, S.; Li, D.; Yohannes, A.; Song, H. Exploration for network distance teaching and resource sharing system for higher education in epidemic situation of COVID-19. Procedia Computer Science, 2021, $183,807-813$.

[19] Lei, Z.; Zhou, H.; Hu, W.; Deng, Q.; Zhou, D.; Liu, Z. W.; Lai, J. Modular web-based interactive hybrid laboratory framework for research and education. IEEE, 2018, 6, 20152-20163.

[20] Wang, N.; Chen, X.; Lan, Q.; Song, G.; Parsaei, H. R.; Ho, S. C.A novel Wiki-based remote laboratory platform for engineering education. IEEE transactions on learning technologies, 2016, 10(3), 331-341.

[21] Wang,X.; Wang, y.; Liu, X. Study on application of management information system in laboratories of soil and water conservation specialty. Experimental Technology and Management(china), 2015,32(10): 142-145,160. 